\title{
A Study on Aerodynamics and Stability Characteristics of a Bell-Shaped Span-Load Wing
}

\author{
Nadhiratul Akmal Ab Razak', Mohd Fadhli Zulkaflii ${ }^{*}$ \\ ${ }^{1}$ Faculty of Mechanical Engineering and Manufacturing, \\ Universiti Tun Hussein Onn Malaysia, Batu Pahat, 86400, Johor, MALAYSIA \\ *Corresponding Author
}

DOI: https://doi.org/10.30880/paat.2021.01.01.005

Received 24 September 2021; Accepted 11 November 2021; Available online 21 December 2021

\begin{abstract}
The existence of the new bell-shaped span-load wing is said to has the best lift distribution especially comparing to the elliptical wing. Bell-shaped span-load wing is designed by configuring the twist of the wing. However, the information on the aerodynamic and stability characteristics of the bell-shaped span-load wing is limited. Thus, the main purpose of the research is to evaluate the aerodynamic and stability characteristic to strengthen the claim of the capability of bell-shaped span-load wing in producing minimum induced drag. As the research is expected to be beneficial to the aviation design team, detailed information regarding the lift distribution as well as the induced drag produced is analysed at the optimum angle of attack and the results is further explained in this research. The numerical method for the analysis is done by using Lifting Line Theory (LLT) in the XFLR5 software which can analyse the wings of aircraft in terms of its aerodynamic and stability characteristic. Then, the comparison of the aerodynamic characteristics for bell-shaped span-load, elliptical span-load and tapered wing done in this research is to strengthen the appeal made stating that the bell-shaped span-load wing is the best type of wing ever existed and may replace the elliptical wing as the best wing shape with aerodynamically most efficient. The research has proven that along the wingspan, the bell-shaped span-load wing produced the lowest and minimum induced drag when being compared. At the optimum angle of attack of bell-shaped span-load wing, though the lift produced is slightly lower than the elliptical and tapered wing, the difference in the induced drag is obvious as bellshaped span-load wing produces induced drag that is lower than 0 . In other words, starting from the semi span of the wing to the wingtip, the bell-shaped span-load wing managed to be the most aerodynamically efficient wing.
\end{abstract}

Keywords: Bell-shaped lift distribution, wing, aerodynamic, stability

\section{Introduction}

Lift force is generated due to the effect of airfoil cross-sectional shape and angle of attack of the wing, which exerts a downwash to the ground as the air flows past around it. Prandtl stated in his theory before [1], the lift distribution across the wing is dependent on the geometry of the wing. A variety of shapes such as curved or straight for either trailing edge or leading edge of an aircraft wing may affect the flight characteristics. For instance, the elliptical span-load wing which was claimed as the best shape for lift distribution, for now, has an elliptical form in the spanwise direction. This is due to its aerodynamical efficiency of producing the least amount of drag.

In 1918, Prandtl introduced a theory called Non-Linear Lifting Line Theory also known as the Prandtl Lifting-line Theory (LLT) which is a tool that enabled the calculation of lift and drag for a given wing [2]. The LLT uses the vortices effects to measure the lift distribution along the span-load. The LLT was first derived for elliptical span-load wing with the application from the Kutta-Joukowsky theorem which was expressed as [3]: 


$$
L^{\prime}=\rho_{\infty} u_{\infty} \Gamma
$$

As Prandtl published his second paper on a superior span-load solution [4], bell-shaped span-load has become a hot topic among aviators. As past studies suggested that there is a better shape with improved aerodynamic and stability characteristics which can also enhance the performance of an aircraft. This wing is called a bell-shaped span-load wing. The wing with bell-shaped span-load characteristics shows a higher efficiency with minimum induced drag produced. Hospodar [5] proved the statement in his paper where it concludes that the bell-shaped span-load has the lowest aerodynamic drag compared to three general wings including rectangular, trapezoidal and elliptical.

In contrast to the elliptical span-load, the bell-shaped span-load describes a wing having a downwash that varies from strong downwash near the wing root, which tapers outboard to upwash near the wingtip, as claimed by Bowers [2]. Prandtl's solution is described as:

$$
L=\left(1-x^{2}\right)^{3 / 2}
$$

Subsequently, after a few derivations, the slope of upwash at the wingtip is equal on both sides of the wingtip as shown in equations (6) where lift approaches zero at wingtip (equation (4)) and slope of lift approaches zero at the wingtip (equation (5)) is as follows. These equations were obtained from the nondimensional downwash angle presented in equation (3).

$$
\begin{gathered}
D W=3 / 2\left(x^{2}-1 / 2\right) \\
\lim _{x=0 \rightarrow b / 2} L(x)=0 \\
\lim _{x=0 \rightarrow b / 2}\left(\frac{d L(x)}{d x}\right)=0 \\
\lim _{x=0 \rightarrow b / 2}\left(\frac{d D W(x)}{d x}\right)=\lim _{x=0 \rightarrow b / 2}\left(\frac{d D W(x)}{d x}\right)
\end{gathered}
$$

Referring to research done by Bragado [6], the outcome obtained was that the bell-shaped span-load wing managed to reduce the induced drag as well as maximise the aerodynamic efficiency for a given loading. It stated that the wing develops into upwash at the tip which eventually creates induced thrust. In addition, the wing shows an increment instability which allows the aircraft to achieve proverse yaw without any control input. However, this statement was opposed by Hainline [7], in which it stated that in order to ensure strong proverse yaw characteristic, it shall be achieved by using control surfaces such as an aileron.

The doubt of better existence shape of wing has been raised in previous studies by Prandtl. Prandtl's research discussed that the bell-shaped span-load might be the best compared to the elliptical wing. According to the past studies, the bell-shaped span-load wing produces lower total drag compared to another wing such as elliptical span-load and tapered wing. According to Bowers [2], this is due to the production of induced thrust whereas the elliptical span-load produces induced drag which has to be controlled by designing a winglet at the wingtip or having a longer wingspan.

However, previous studies were not able to prove whether the efficiency of the bell-shaped lift distribution is either based on any values of angle of attack or based on a certain angle of attack. Instead, previous studies only claim proverse yaw to be the solution for the induced drag produced which was also not proven in any research by both Prandtl and Horten. Thus, it cannot be proven whether the drag produced by the bell-shaped span-load produced is naturally least or the induced thrust produced to counteract the drag. Therefore, a detailed study on aerodynamic characteristics such as thrust, drag and lift generation as well as the stability characteristic of the bell-shaped span-load wing is needed.

\section{Methodology}

The research is done by using XFLR5 software which is capable in analysing the aerodynamic and stability characteristics. XFLR5 software is an analysis tool for airfoils, wings and planes which operates at low Reynold Numbers based on the Lifting Line Theory, Vortex Lattice Method and on a 3D Panel Method [8]. XFLR5 is capable to extract data on the lift distribution across the wing in the form of graphs for better analysis. The study is expected to execute beneficial aerodynamic and stability information from the software.

In this study, The analysis was run by using the Lifting Line Theory method, which is capable of extracting the lift distribution over a three-dimensional wing based on its geometry. As an additional to the lift distribution provided by the theory, the induced drag can also be analytically proven as acting on the finite lifting surface [9]. The LLT method is best used as the non-linear lift curve obtained as it executes the most realistic trend [10]. Thus, different configurations are made to obtain the lift distribution required. 


\subsection{Bell-shaped Span-load Wing}

In completing the research on the chosen bell-shaped span-load wing, the design on the wing is required to allow the XFLR5 software to extract data and graphs related. The specific airfoil used for the study is NACA 0012. Thus, the configurations of the wing were based on the characteristics shown in Table 1. However, several configurations need to be altered to achieve a bell-shaped span-load as desired. As shown in Table 2, an amount of twist was added to the configurations. The wing with the bell-shaped span-load wing designed from the XFLR5 software is as shown in Fig. 1.

Table 1 - NACA 0012 airfoil wing configurations

\begin{tabular}{ccc}
\hline No. & Characteristics & Values \\
\hline \hline $\mathbf{1 .}$ & Wing Area $(\mathrm{m} 2)$ & 0.15 \\
\hline $\mathbf{2 .}$ & Wingspan $(\mathrm{m})$ & 1.000 \\
\hline $\mathbf{3 .}$ & Root Chord $(\mathrm{m})$ & 0.500 \\
\hline $\mathbf{4 .}$ & Tip Chord $(\mathrm{m})$ & 0.250 \\
\hline $\mathbf{5 .}$ & M.A.C. $(\mathrm{m})$ & 0.172 \\
\hline $\mathbf{6 .}$ & Aspect Ratio & 6.667 \\
\hline $\mathbf{7 .}$ & Taper Ratio & 5.000 \\
\hline $\mathbf{8 .}$ & Sweep Angle $\left(^{0}\right)$ & $34.992^{\circ}$ \\
\hline
\end{tabular}

Table 2 - Twist distribution. [11]

\begin{tabular}{lccc}
\hline No. & Span $(\mathbf{m})$ & Chord Length $(\mathbf{m})$ & Angle of Twist $(\mathbf{o})$ \\
\hline \hline 1. & 0 & 0.250 & 7.56 \\
\hline 2. & 0.05 & 0.230 & 6.69 \\
\hline 3. & 0.10 & 0.210 & 5.81 \\
\hline 4. & 0.15 & 0.190 & 4.92 \\
\hline $\mathbf{5 .}$ & 0.20 & 0.170 & 4.01 \\
\hline 6. & 0.25 & 0.150 & 3.07 \\
\hline 7. & 0.30 & 0.130 & 2.11 \\
\hline 8. & 0.35 & 0.110 & 1.12 \\
\hline 9. & 0.40 & 0.090 & -0.10 \\
\hline 10. & 0.45 & 0.070 & -1.03 \\
\hline 11. & 0.50 & 0.050 & -2.05 \\
\hline
\end{tabular}
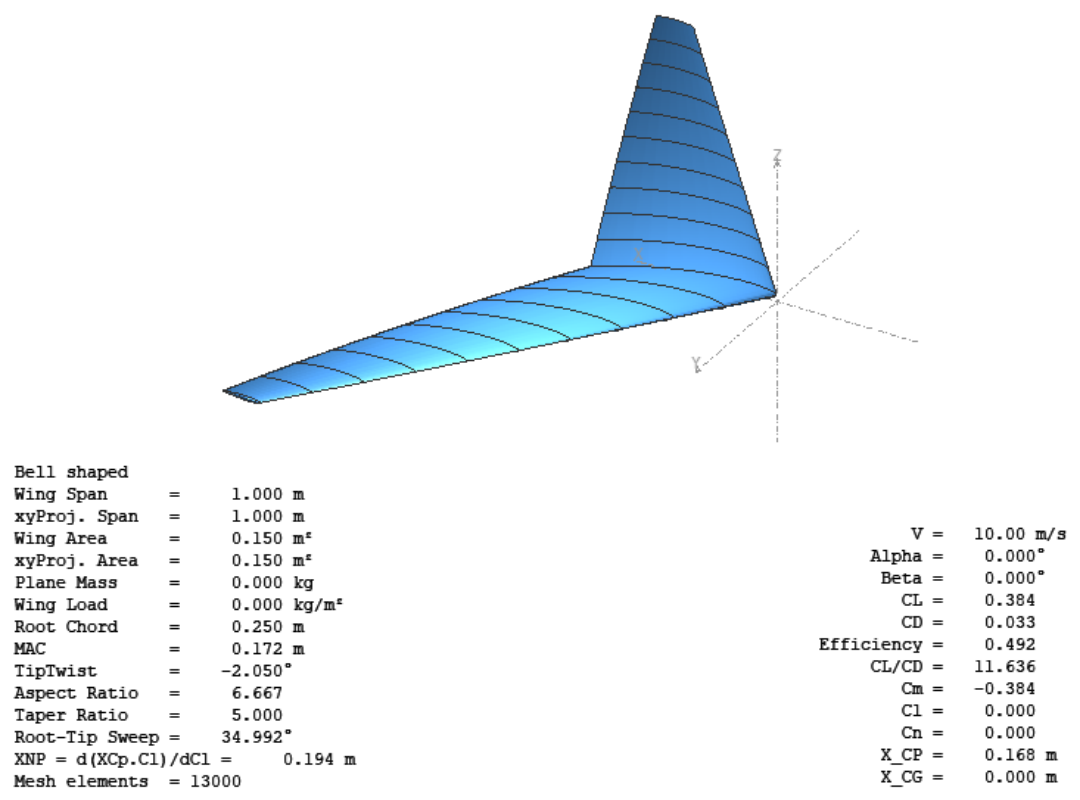

Fig. 1 - Bell-shaped span-load wing obtained from XFLR5 software 


\subsection{Elliptical Span-load and Tapered Wing}

The two designs of elliptical and tapered span-load airfoils were used to compare the efficiency of Prandtl's second outcome of research, bell-shaped span-load. The research used NACA 0012 as the selected airfoil with the provided specifications as shown in Table 3 and Table 4.

Table 3 - NACA 0012 airfoil wing specification for elliptical span-load wing

\begin{tabular}{lcc}
\hline No. & Characteristics & Values \\
\hline \hline $\mathbf{1 .}$ & Wing Area $\left(\mathrm{m}^{2}\right)$ & 0.15 \\
\hline $\mathbf{2 .}$ & Wing Span $(\mathrm{m})$ & 1.0 \\
\hline $\mathbf{3 .}$ & Root Chord $(\mathrm{m})$ & 0.150 \\
\hline $\mathbf{4 .}$ & Tip Chord $(\mathrm{m})$ & 0.150 \\
\hline $\mathbf{5 .}$ & M.A.C. $(\mathrm{m})$ & 0.15 \\
\hline $\mathbf{6 .}$ & Aspect Ratio & 6.667 \\
\hline $\mathbf{7 .}$ & Taper Ratio & 1.0 \\
\hline
\end{tabular}

Table 4 - NACA 0012 airfoil wing specification for tapered wing

\begin{tabular}{lcc}
\hline No. & Characteristics & Values \\
\hline \hline $\mathbf{1 .}$ & Wing Area $\left(\mathrm{m}^{2}\right)$ & 0.15 \\
\hline $\mathbf{2 .}$ & Wing Span $(\mathrm{m})$ & 1.0 \\
\hline $\mathbf{3 .}$ & Root Chord $(\mathrm{m})$ & 0.200 \\
\hline $\mathbf{4 .}$ & Tip Chord $(\mathrm{m})$ & 0.150 \\
\hline $\mathbf{5 .}$ & M.A.C. $(\mathrm{m})$ & 0.15 \\
\hline $\mathbf{6 .}$ & Aspect Ratio & 6.667 \\
\hline $\mathbf{7 .}$ & Taper Ratio & 2.0 \\
\hline $\mathbf{8 .}$ & Root-Tip Sweep & $-0.573^{\circ}$ \\
\hline
\end{tabular}

The Table 3 is the configuration used to design the elliptical span-load wing in the form of a rectangular wing with a taper ratio of 1, while Table 4 shows the settings that need to be made in order to obtain both elliptical span-load and tapered wing. The crucial thing in designing the wings shown Fig. 2 and Fig. 3 was the wing area which has only slight differences for the three wings to obtain the almost similar lift distribution. This is to ensure the aerodynamic comparison is not far from each other.

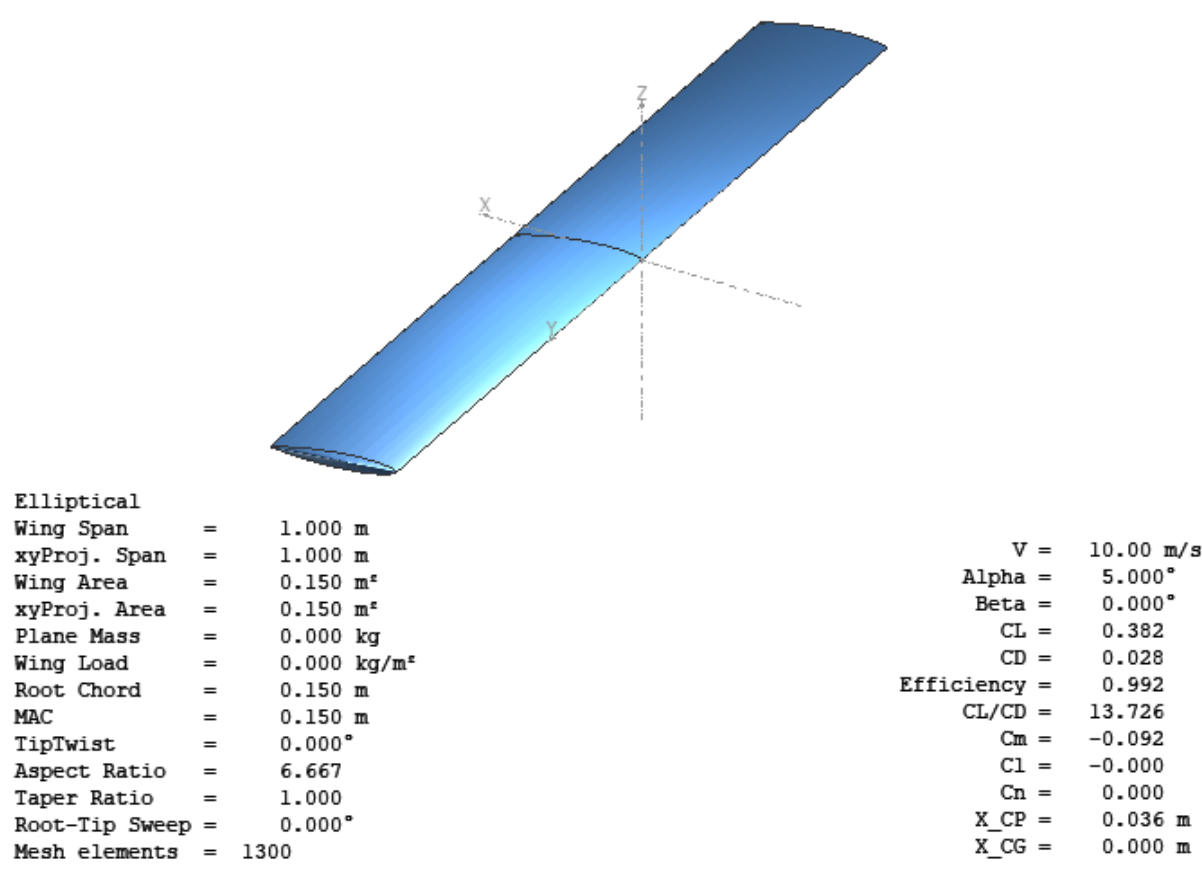

Fig. 2 - Elliptical span-load wing 

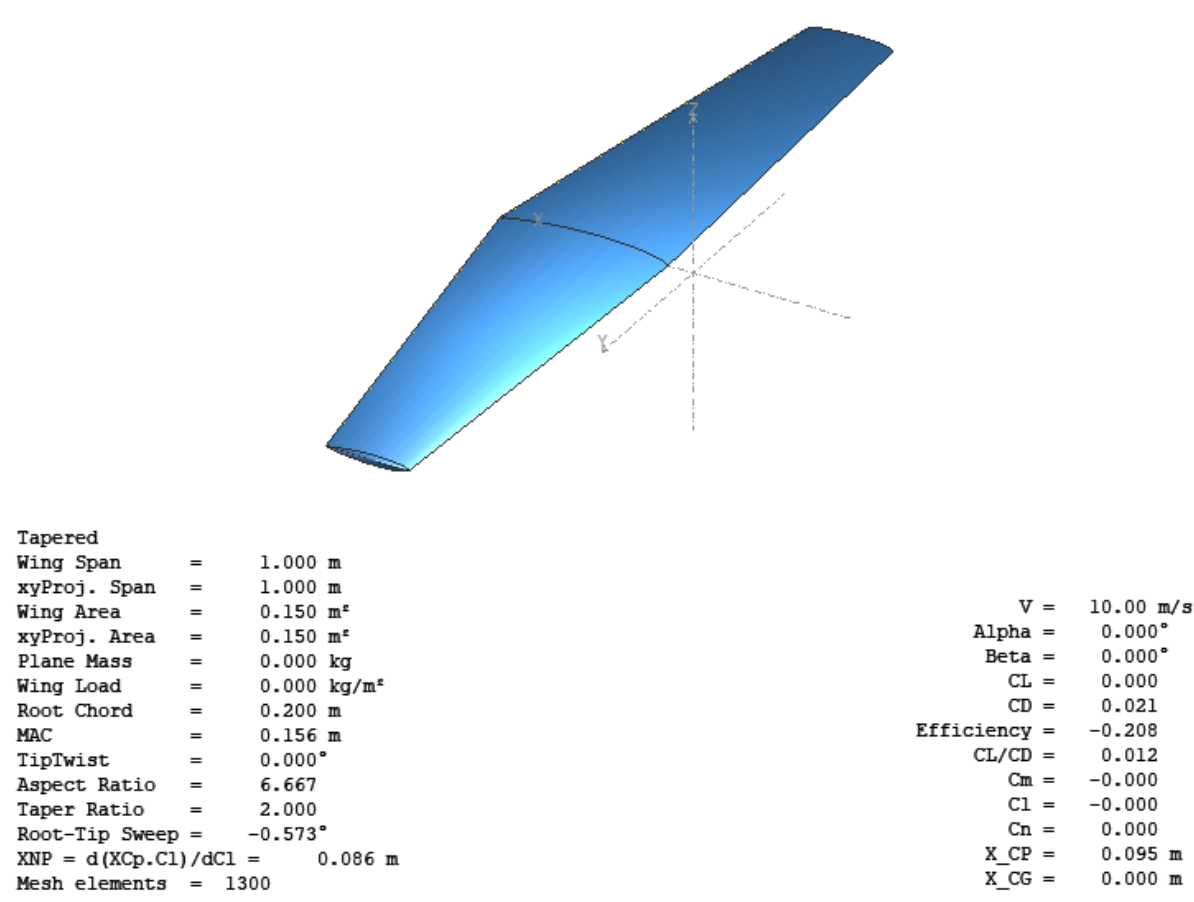

Fig. 3 - Tapered wing

\section{Results and Discussion}

The analysis displayed in this chapter is executed by XFLR5 and further discussion is made according to the graph obtained. The characteristic of the bell-shaped lift distribution is described in terms of its aerodynamic and stability.

\subsection{Bell-shaped Span-load Wing}

As shown in Fig. 4, the observation of the graph represents that $C_{L} / C_{D}$ value increases from $-3^{\circ}$ to the optimum angle of attack of $1.5^{\circ}$. The best lift to drag ratio can be seen at the optimum angle of attack is approximately 13 , before it started to decrease. The efficiency of the bell-shaped span-load is a no doubt as at $0^{\circ}$ angle of attack, the value of lift coefficient is approximately 0.4 as shown in Fig. 4 on the right side. These data shows that lift is still capable to be generated even at $0^{\circ}$ due to the shape of the lift distribution.

a

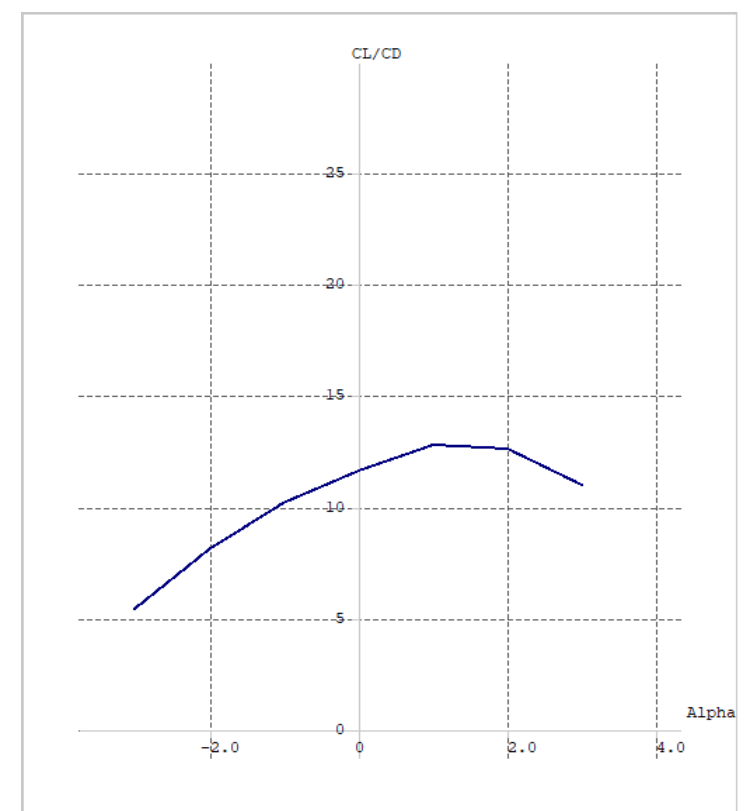

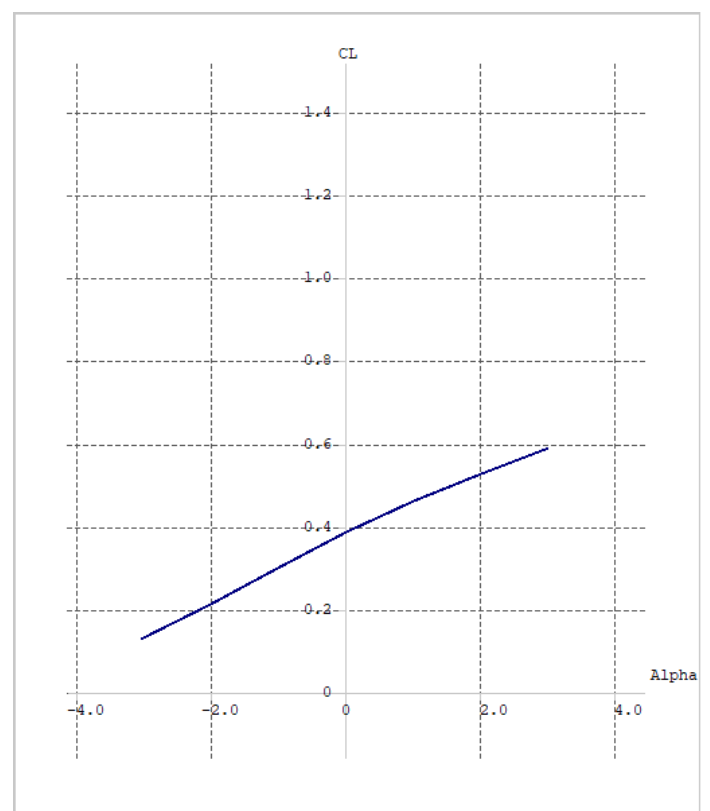

Fig. 4 - Graph of (a) $C_{L} / C_{D}$ against AoA; (b) $C_{L}$ against AoA 
In the comparison of both graphs shown in Fig. 5 and Fig. 6, the induced drag produced from 0.3 of the wingspan to the wing tip is minimum and even below 0 . This strengthens the fact of negative induced drag is produced by the bellshaped span-load wing even though with the presence of lift similar as reported by Bowers [4]. The result of the negative induced drag also indicates that the induced drag act in the same direction as the thrust, which also means the wing produce additional thrust from the aerodynamic force. This is an advantage as it is good for fuel efficiency for the aircraft with the bell-shaped span-load wing.

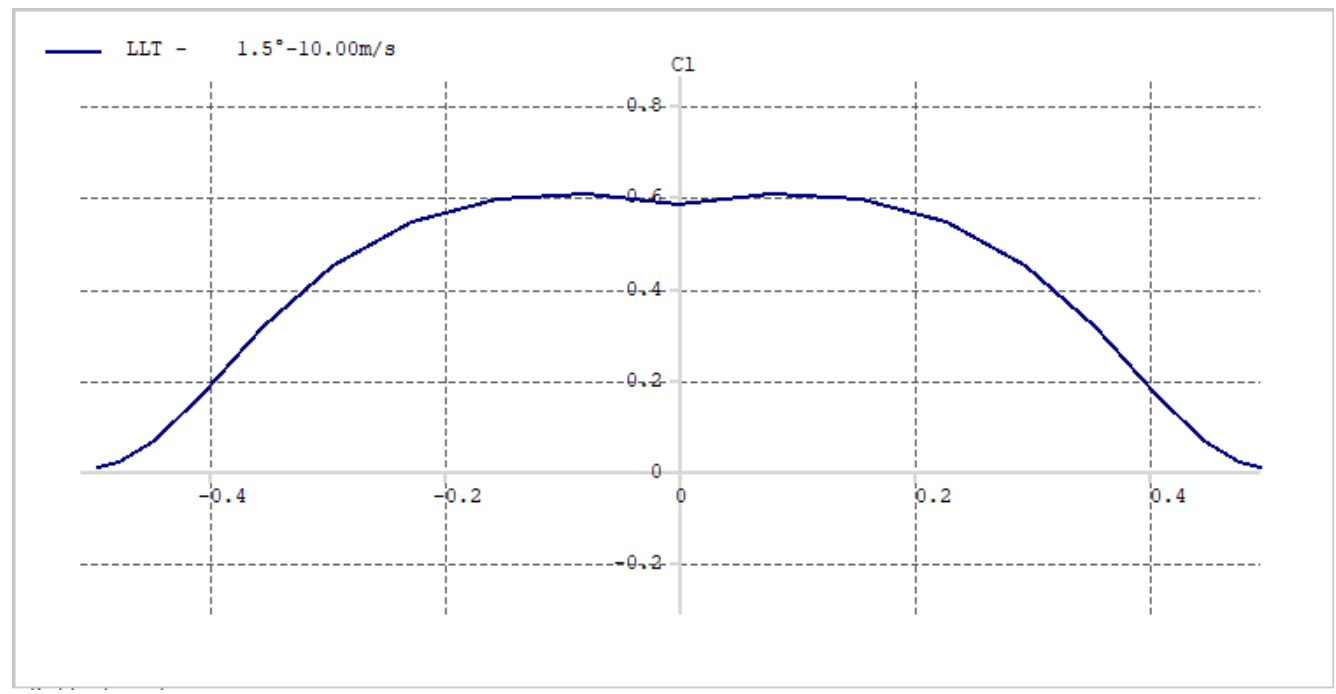

Fig. 5 - Graph of $C_{L}$ along wingspan at optimum AoA

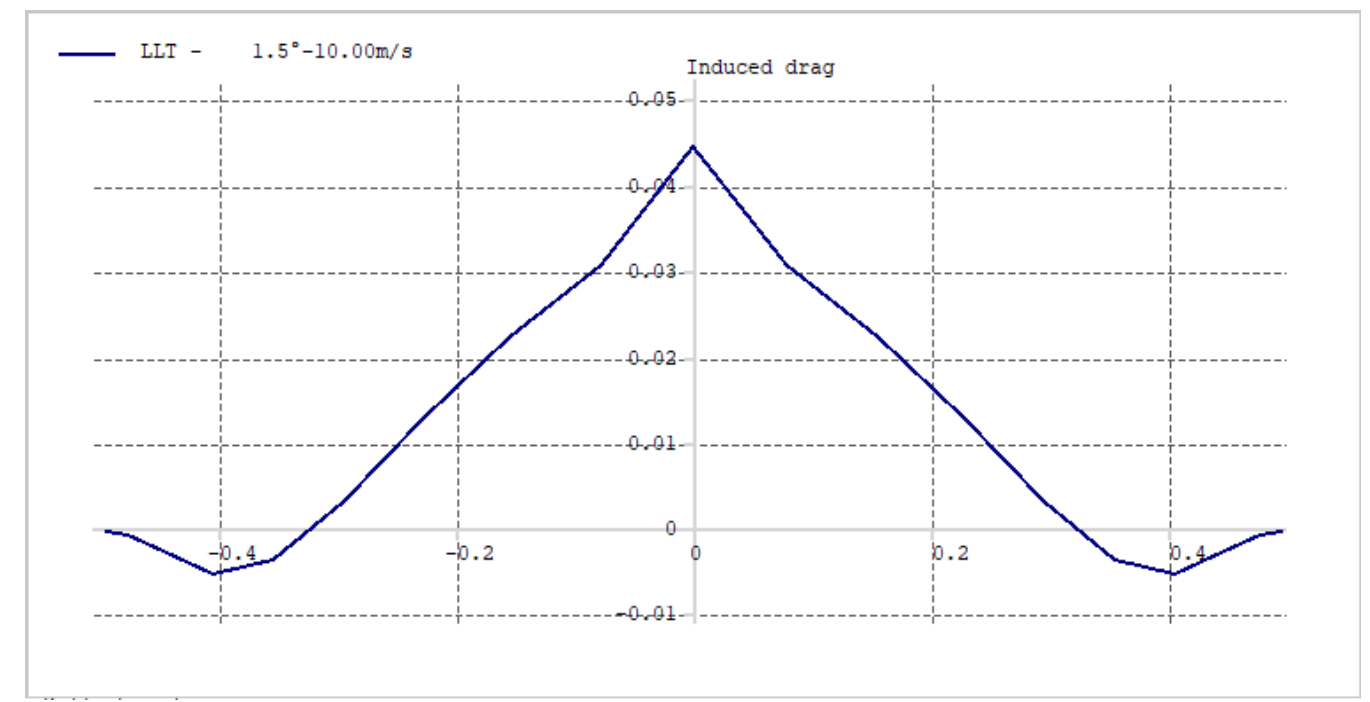

Fig. 6 - Induced drag produced along the wingspan of bell-shaped span-load at optimum AoA

The stability characteristic that is able to be executed from the XFLR5 software is in terms of the moment coefficient, $C_{m}$. As the negative slope indicate stability, the polar curve shown on the left side of Fig. 7 portrays the centre of gravity, $\mathrm{CG}$ is forward of the neutral point, NP which indicates the stability of the wing. The bell-shaped span-load wing is selfstable as the zero-lift moment is positive indicating the wing has a positive static stability characteristic. The wing has the tendency to return to its trim whenever the disturbance such as gust increase its AoA or $C_{L}$ Interestingly, if the line produced by the graph is extrapolated or extended to $C_{m}=0$ line, the wing trims at a small value of positive $C_{L}$.

\subsection{Comparison of bell-shaped span-load, elliptical span-load, and tapered wing}

Subsequently, Fig. 8(a), (b) and (c) show the downwash vector produced by bell-shaped span-load, elliptical span-load and tapered wing, respectively. The results stated that bell-shaped lift distribution produces the largest amount of downwash, followed by elliptical and tapered by which both elliptical span-load and tapered wing have an almost similar amount of downwash. As downwash affected the induced drag, the bell-shaped span-load wing produced the highest amount of induced drag shown in Fig. 8. 
The phenomenon is common, as induced drag is the result of airfoil producing lift. Thus, the higher lift generated, the higher induced drag produced. The induced drag is said to be affected by the aspect ratio of the wing, however, the aspect ratio for all wings in this study is the same, which is 6.667. Thus, the induced drag produced is based on the lift itself.

a

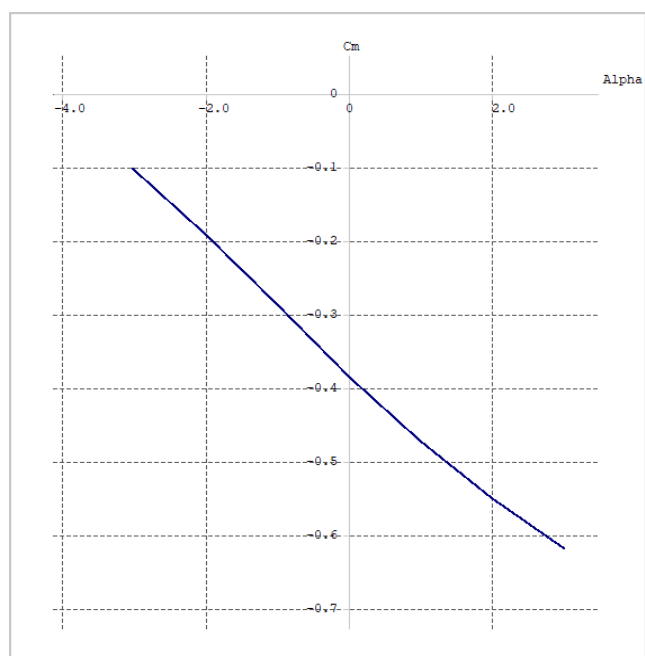

b

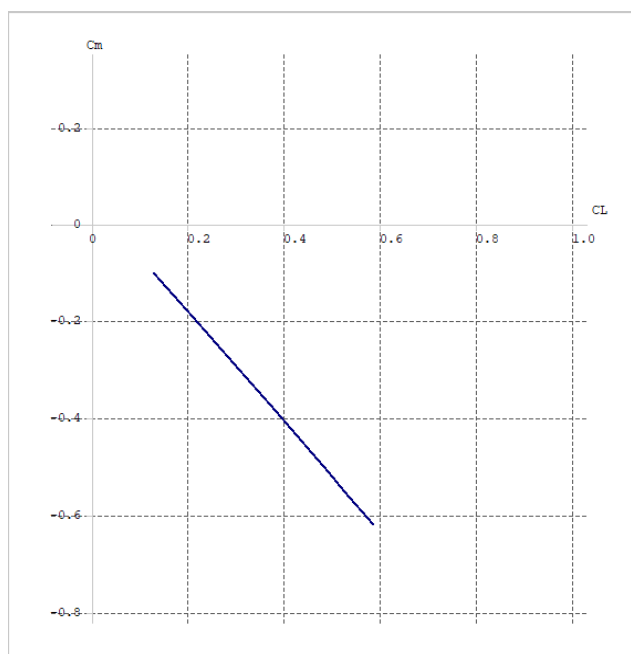

Fig. 7 - Graph of (a) $C_{m}$ against AoA; (b) $C_{m}$ against $C_{L}$

a

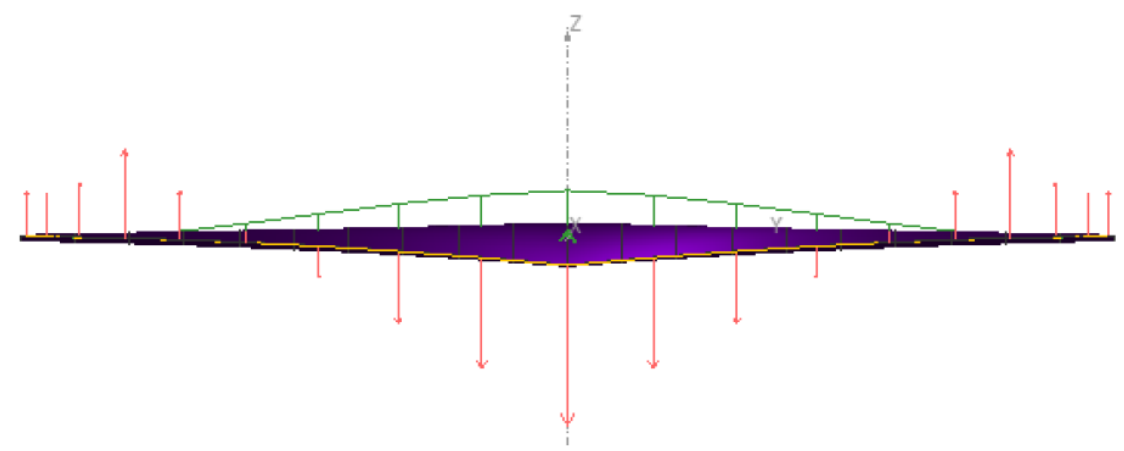

$\mathrm{b}$

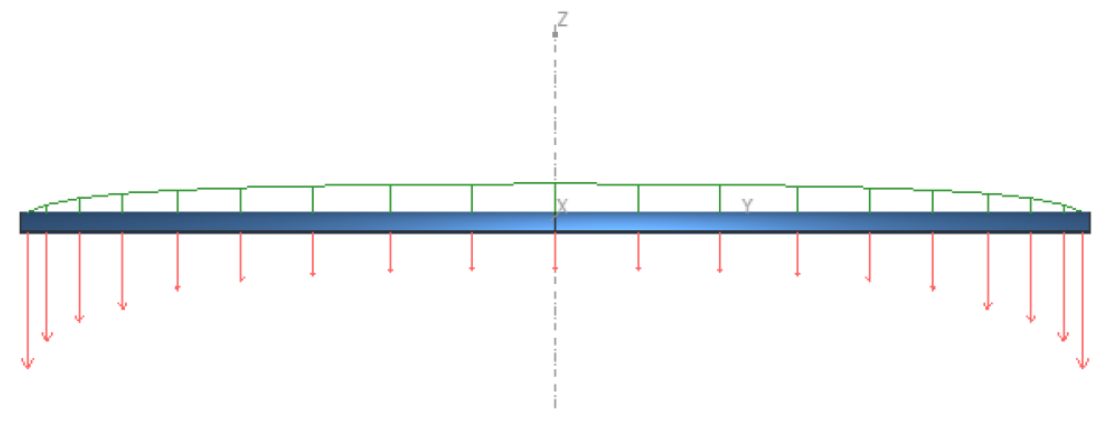

$\mathrm{c}$

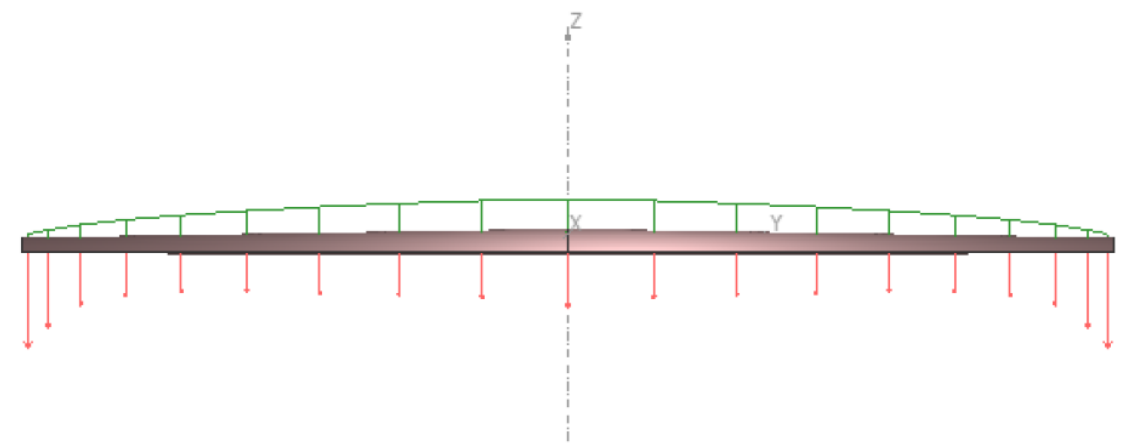

Fig. 8 - Downwash vector of (a) bell-shaped span-load wing; (b) elliptical span-load wing; (c) tapered wing 


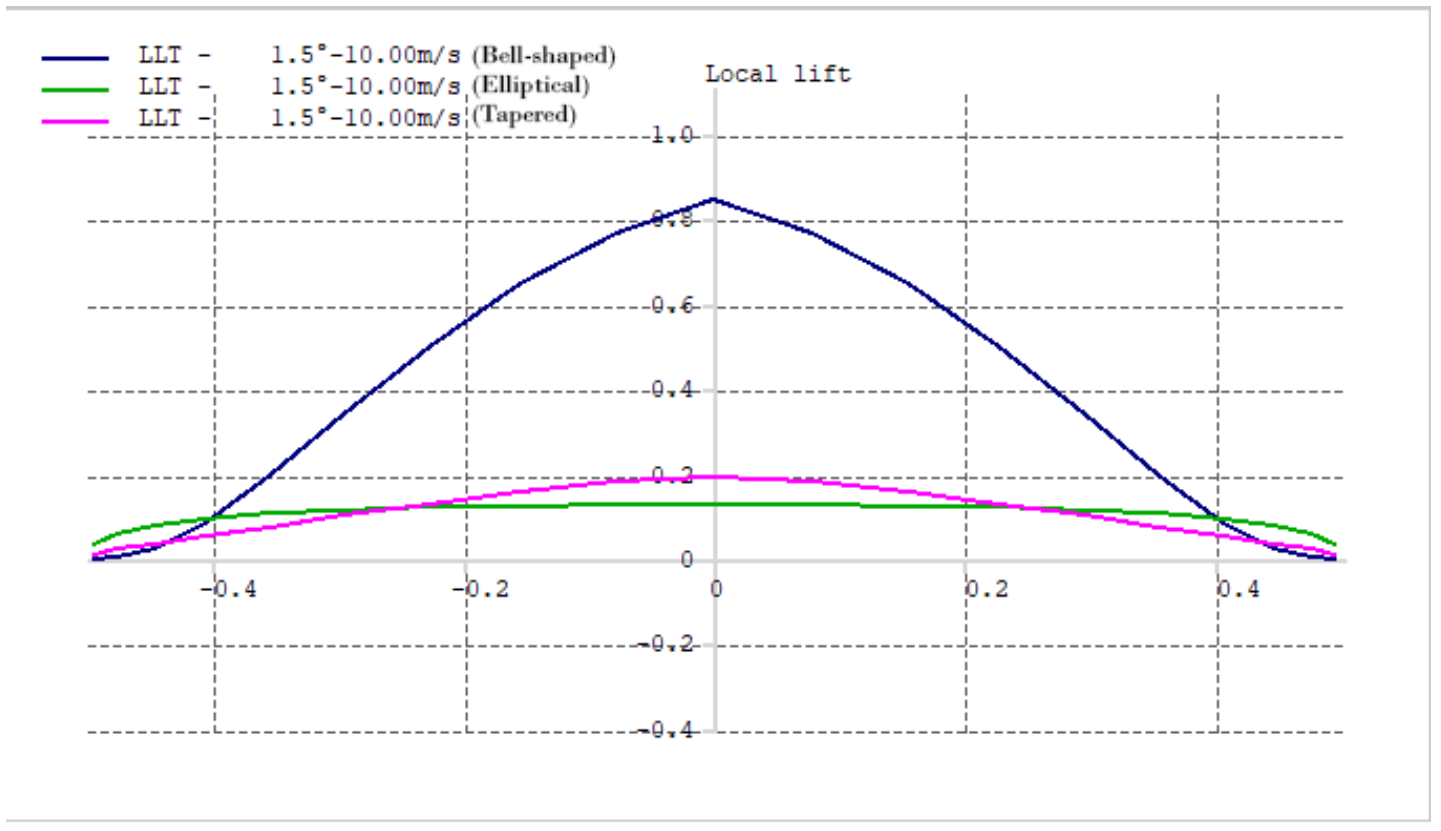

Fig. 9 - Local lift distribution along the wingspan

The lines presented in Fig. 9 represents each wing analysed. The blue, green and pink coloured line is for bell-shaped, elliptical, and tapered types of wing lift distribution, respectively. Direct graph interpretation, bell-shaped span-load has the highest lift produced compared to both elliptical and tapered wings. However, approaching the wingtip, the lift distribution of the bell-shaped span-load wing is considered the lowest among the wings.

Fig. 10 shows the graph of induced drag along the wingspan produced by the wings at the optimum angle of attack of bell-shaped lift distribution, $1.5^{\circ}$. The high amount of induced drag produced at the centre of the wingspan is unreliable as at the centre is not even the root wing. However, along the wingspan, specifically approaching the wingtip, the amount of induced drag for the bell-shaped span-load wing is relatively lower than both elliptical and tapered wings. Thus, proving the fact that induced drag produced by the bell-shaped span-load wing is minimum as stated by previous research.

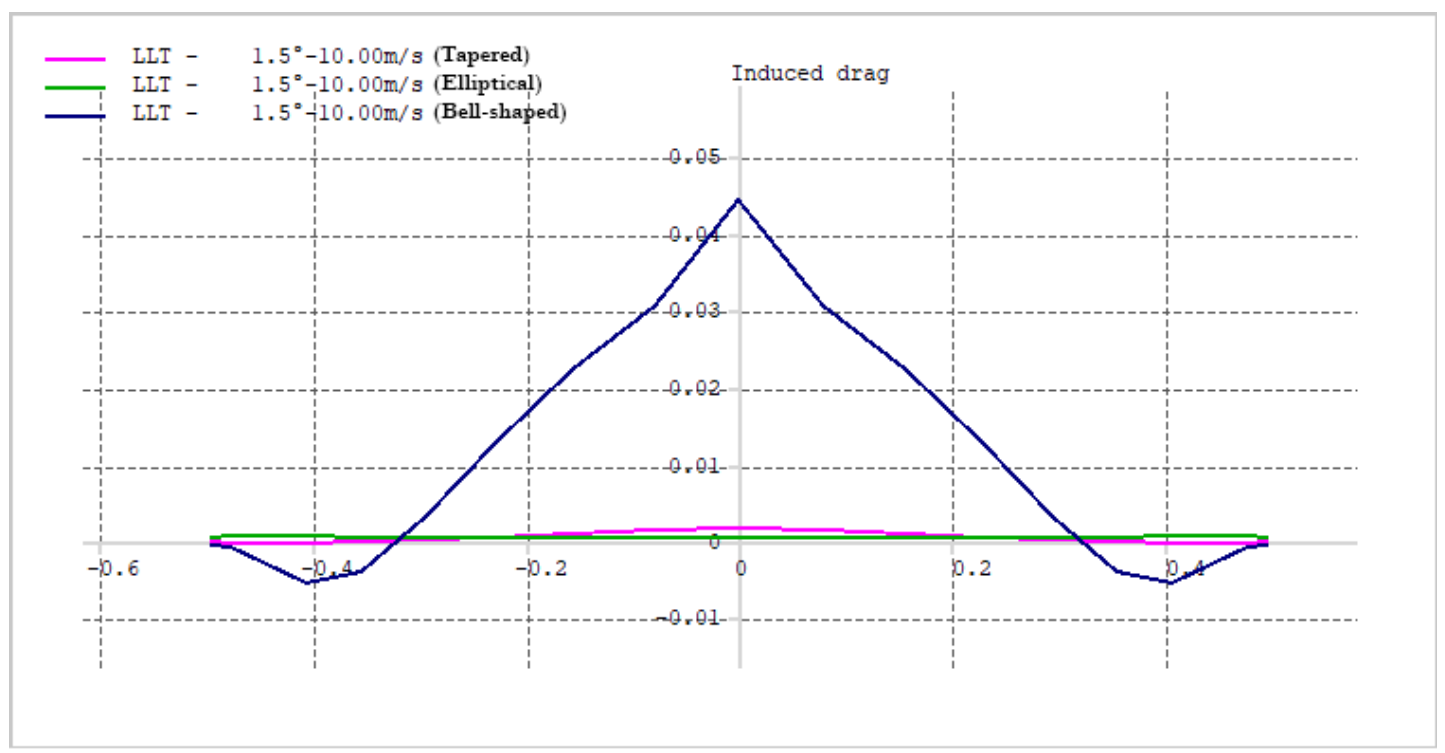

Fig. 10 - Induced drag produced by all wings

Considering the lift to drag ratio graph executed in Fig. 11, the lift to drag ratio increases and it reaches the maximum value at some AoA. Then, as the AoA increases further, the lift to drag ratio decreases as the induced drag increase even though the $C_{L}$ still increase. Mentioned by Nordian in its book, the behaviour is caused by exceeding values of $C_{L}$ in comparison to $C_{D}$ [12]. The equation (7) represents the relation between the $C_{L}$ and induced drag coefficient, $C_{D_{i}}$, where $K$ is a constant parameter that involve wing aspect ratio and Ostwald factor. Thus, the higher $C_{L}$ will lead to more increment of the $C_{D_{i}}$ and causing the lift to drag ratio to be decreased. 


$$
C_{D_{i}}=K C_{L}^{2}
$$

In the case of the bell-shaped span-load wing, though with the same speed of $10 \mathrm{~m} / \mathrm{s}$, it is capable to produce higher lift compared to elliptical and tapered wing, specifically during low AoA such as $0^{\circ}$. This remarks that the efficiency of bell-shaped span-load is at its best when the AoA is low.

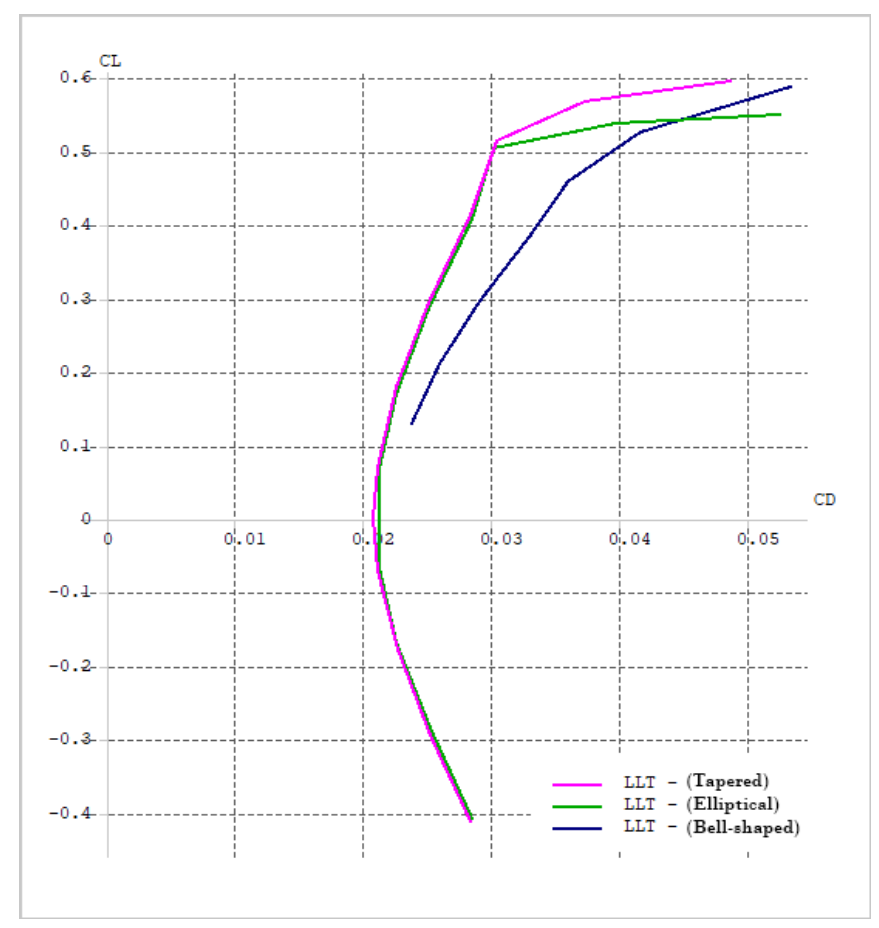

Fig. 11 - Graph of $C_{L} / C_{D}$ against AoA for all wings

As shown, the optimum angle of attack for both elliptical and tapered span load that produces maximum lift to drag ratio is relatively higher than the bell-shaped span-load with approximately 16 for the lift to drag ratio at the AoA of $5^{\circ}$. On the other hand, the optimum angle of the bell-shaped span-load wing is at $1.8^{\circ} \mathrm{AoA}$ with a value of lift to drag ratio of 12. Therefore, the bell-shaped span-load wing has a lower optimum angle of attack compared to both elliptical and tapered which affect the performance of the wing to be not the best as compared to the others in terms of its optimum angle performance.

\section{Conclusion}

The lift distribution obtained for bell-shaped through the XFLR5 software can be said to vary throughout different angle of attack. As the angle of attack increases, the lift distribution at the root wing is observed to be decreasing. However, the bell-shaped span-load wing has proven that it may produce negative minimum induced drag though with presence of lift. The bell-shaped span-load wing executes expected results of the relation between lift and induced drag where the higher the lift, the higher the induced drag generated. Noticeably, the result showed that from the semi span to the wingtip of the bell-shaped span-load, the induced drag is beyond 0 .

On the other hand, the stability of the bell-shaped span-load wing needed to be further studied as the result obtained from the XFLR5 portrayed the wing is not complete as the graph produced by the XFLR5 is limited. Still, considering the estimated graph of $C_{m}$ against AOA, the zero-lift moment coefficient of the bell-shaped span-load wing is positive. Thus, implying that the bell-shaped span-load wing is capable of flying and is considered stable. The statement is strengthened by the fact that when the result shows a positive zero-lift moment coefficient, it means that the wing is selfstable and the help of the stabilizer is unnecessary. Yet, the idea of having a stabilizer to increase the stability of the wing cannot be rejected.

The claim made by Prandtl in his study which stated that the bell-shaped span-load wing is the best wing compared to both elliptical and tapered wing is confirmed. This is due to the induced drag produced by the bell-shaped lift distribution. Though with an almost similar amount of lift generated along the semi span wing to the root wing, the induced drag produced by the bell-shaped lift distribution is spectacularly low when compared to the other wings. 


\section{Acknowledgement}

The authors would like to thank the Faculty of Mechanical and Manufacturing Engineering, Universiti Tun Hussein Onn Malaysia for giving the opportunity to conduct this study.

\section{References}

[1] L. Prandtl, "Applications of modern hydrodynamics to aeronautics," US Government Printing Office, 1921

[2] A. H. Bowers, O. J. Murillo, R. R. Jensen, B. Eslinger, and C. Gelzer, "On Wings of the Minimum Induced Drag: Spanload Implications for Aircraft and Birds,” Nasa/Tp-2016-219072, no. March, pp. 1-22, 2016

[3] C. K. Madnia, Review of "Fundamentals of Aerodynamics, ” vol. 48, no. 12. 2010. doi: 10.2514/1.52157

[4] W. Tollmien, H. Schlichting, H. Görtler, and F. W. Riegels, "Über tragflügel kleinsten induzierten widerstandes," in Ludwig Prandtl Gesammelte Abhandlungen, Springer, 1961, pp. 556-561

[5] P. Hospodář and A. Drábek, "Comparison of aerodynamic characteristics provided by wing with bell shaped lift distribution and generalized wings," MATEC Web of Conferences, vol. 304, p. 02005, 2019, doi: 10.1051/matecconf/201930402005

[6] E. Bragado, S. Fraysse, and M. Lone, "Aerodynamic and flight dynamic study of wings with non-elliptic lift distributions," 2019. doi: 10.2514/6.2019-0820

[7] K. Hainline and R. K. Agarwal, “Aerodynamic Study of Stability and Control of Straight Flying-Wings,” 2017. [Online]. Available: https://openscholarship.wustl.edu/mems500https://openscholarship.wustl.edu/mems500/49

[8] "Guidelines for QFLR5 v0.03 XFLR5 Analysis of foils and wings operating at low Reynolds numbers," 2009. Accessed: $\quad$ Dec. 2021. [Online]. Available: https://engineering.purdue.edu/ aerodyn/AAE333/FALL10/HOMEWORKS/HW13/XFLR5_v6.01_Beta_Win3 $2 \% 282 \% 29 /$ Release/Guidelines.pdf

[9] E. Pakalnis, "Lift And Drag Force Calculation Methods Using Non-Linear Section Data. History And Recent Research," Aviation, vol. 8, no. 2, pp. 9-13, 2004, doi: 10.1080/16487788.2004.9635869

[10] A. Deperrois, “About XFLR5 Calculations and Experimental Measurements,” ReVision, no. October, 2009

[11] V. Bembrekar, A. Rasane, A. Jadhav, O. Vaishnav, and S. Mirdude, "Design of a Wing with Bell-shaped Spanload using VLM Method," International Journal of Engineering Trends and Technology, vol. 59, no. 4, pp. 182185, 2018, doi: 10.14445/22315381/ijett-v59p233

[12] "Nordian Principles Of Flight (A) (5D)," in Textbook, EASA EDITI., Nordian, 2008, pp. 4-10 